\title{
Identification and Prioritization of Constraints in Umblachery Breed Cattle Farming Through Participatory Approach
}

\author{
M.S. Kannadhasan ${ }^{1 *}$, M. Kathirchelvan ${ }^{2}$ and R. Rajendran ${ }^{3}$ \\ ${ }^{1}$ Veterinary University Training and Research Centre, Tamil Nadu Veterinary Animal \\ Sciences University (TANUVAS), Dharmapuri - 636701, Tamil Nadu, India \\ ${ }^{2}$ Farmers Training Centre, TANUVAS, Tiruvarur-610 004, Tamil Nadu, India \\ ${ }^{3}$ Post Graduate Research Institute in Animal Sciences, TANUVAS, Kattupakkam - 603203, \\ Tamil Nadu, India \\ *Corresponding author
}

\section{A B S T R A C T}

\section{Keywords}

Identification,

Prioritization,

Umblachery breed

cattle, Participatory approach

\section{Article Info}

Accepted:

10 October 2018

Available Online:

10 November 2018
Umblachery cattle are well-known indigenous breed for its draught power in Cauvery delta region. Conservation of Umblachery cattle breed gained importance in recent years. In this background, the study with the financial assistance from Tamil Nadu Veterinary and Animal Sciences University Research Corpus Fund (TRCF) was conducted at Umblachery, a native village of Umblachery breed tract in Nagapattinam district, Tamil Nadu to identify and prioritize the constraints in Umblachery breed cattle farming faced by farmers through participatory approach. Thirty progressive farmers in and around Umblachery village who were selected applying purposive random sampling technique, participated in focused group discussion to identify the constraints followed by personal interview to prioritize the constraints and group discussion to find the possible reasons behind constraints. The entire participatory method was carried out with the help of Department of Animal Husbandry, Tamil Nadu and representatives of Non-Governmental Organizations (NGOs) and Famers' association. Individually prioritized scores on the farmers' identified 15 constraints were subjected into Garrett ranking method to measure the significance. The results revealed that the lack grazing land having highest Garrett table mean score of 79.37 as the most important and serious constraint followed by improper maintenance of ponds (72.30), feed deficit (59.30), mechanization (53.77), dominance of fertilizer (51.60), inadequate farmers club (49.17), lack of bull (48.75), dominance of cross-bred animals (43.56), lower price of animals and its products on sale (42.55), unregulated marketing (39.44), lack of awareness about technologies (38.86), indiscriminate breeding (34.06), record maintenance (32.66), natural disaster proneness (30.58) and deficit of manpower (26.87). The results will foster the policy makers involved in Umblachery cattle breed conservation to develop and implement appropriate strategies to overcome the constraints in Umblachery breed cattle farming. 


\section{Introduction}

India is bestowed with rich domestic animal biodiversity with 30 breeds of cattle, 10 breeds of buffaloes, 42 breeds of sheep, 30 breeds of goats, 8 breeds of camels, 6 breeds of horse and 18 breeds of poultry in addition to other species like pig, donkey, mithun, yak, turkey, duck, etc. Genetic resources are the building blocks of sustainable agriculture (Bishop et al., 2002).

Tamil Nadu is the home of well-known draught breeds of cattle, such as Kangayam, Umblachery, Bargur, Alambadi and Pulikulam. Umblachery breed, also known by the synonyms Mottai madu, Molai madu, Jathi madu and Therkathi madu, is a reputed draught breed of Thanjavur, Thiruvarur and Nagapattinam districts in eastern parts of Tamilnadu state in south India. This breed is the outcome of selection for short stature, suitable for work in marshy rice fields of Cauvery deltaic region (Thangaraju et al., 2001). Umblachery breed is noted for its strength and sturdiness especially used in the marshy fields for wet ploughing. The cows are poor milkers. The white star on forehead, white socks markings in four legs and white tail switch are the specific characteristics of this breed. The habitat of this breed is in the Cauvery delta region, the rice granary of Tamil Nadu. The breeding tract of this breed has shrunken over the years. Intensive agriculture with mechanization and the dominance of exotic breeds and cross breeds has reduced the role of indigenous cattle breed (Taneja, 2011).

Genetic value of an animal is determined not only due to its production, but also due to its adaptability to existing environment, utilization of available feed resources and particularly to the level of resistance to local diseases (Radhika et al., 2010). It is difficult to save them, unless they are made economical under the prevailing production systems (Choubey and Thomas, 2010). The United Nations proclaimed the year 2010 to be the International Year of Biodiversity, and people all over the world are working to safeguard this irreplaceable natural wealth and reduce biodiversity loss. Hence, the major thrust in draught animal welfare should be improvement of the productivity of draught animals through scientific and technological inputs (Ramaswamy, 1994). A report of FAO stated that the neglect of animal power technology in recent years affected the availability of essential information. In such circumstances, participatory appraisal surveys may be required to study the present uses of work animals, the existing constraints and the future potential.

Increasingly, the constraints to animal power development are psychological or social rather than technical or economic. These calls for an immediate action for identifying and prioritizing the constraints faced by the farmers in Umblachery breed cattle farming.

\section{Materials and Methods}

The study was conducted through participatory approach to identify the constraints perceived by the farmers and how are they in consonance with the perception of farmers group. It was conducted at Umblachery village, believed as the native village of the breed in Nagappattinam district, Tamil Nadu. Thirty progressive farmers who are actively involved in Umblachery cattle farming in and around Umblachery village were identified and selected applying purposive random sampling technique with the help of Department of Animal Husbandry and Traditional Umblachery Cattle Farmers' Association. Purposive selection method was followed to ease the application of participatory methods in identification and prioritization of the constraints perceived by 
the farmers Umblachery breed cattle farming. Initially, a focused group discussion among the farmers was conducted to identify the constraints perceived by the farmers who are rearing Umblachery breed cattle. Then, personal interview was conducted with each respondent to prioritize the constraints perceived by him/her from the identified 15 constraints. The responses recorded from respondents were simultaneously entered, analysed and prioritized using Garrett ranking calculation.

\section{Garrett ranking technique}

Garrett ranking technique was used to rank the constraints perceived based on its seriousness and significance by farmers involved Umblachery breed cattle farming. The order of priority and severity of the constraints given by the respondents was converted into ranks by using following formula.

Percentage position $=\frac{100\left(\mathrm{R}_{\mathrm{ij}}-0.5\right)}{\mathrm{N}_{\mathrm{j}}}$

Where,

$R_{i j}=$ Rank given for the ith variable by $j^{\text {th }}$ respondent

$\mathrm{N}_{\mathrm{j}}=$ Number of variable ranked by $\mathrm{j}^{\text {th }}$ respondent

With the help of Garrett's table, the percent position estimated is converted into scores. Then for each constraint, the scores of each individual are added and total value of scores and mean values of score is calculated. The constraint having highest mean value is considered to be the most important constraint

Finally, a group discussion was conducted to discuss the possible reasons behind the prioritization of identified constraints. The entire participatory method was carried out among the farmers by encouraging them to accomplish the participatory approach in the presence and with the guidance of Veterinarians from the Department of Animal Husbandry, Tamil Nadu and representatives of Non-Governmental Organizations (NGOs) and Traditional Umblachery Cattle Farmers Association.

\section{Results and Discussion}

\section{Identification and grouping of constraints}

The focused group discussion among the Umblachery breed cattle farmers revealed that there were fifteen perceived constraints in which each six constraints were grouped under individual and social constraints and the remaining three under constraints of both individual and social as listed in Table 1.

\section{Prioritizations of identified constraints}

The results obtained subjecting the collected response into Garrett ranking method showed in Table 2 clearly envisaged that of the identified constraints social constraints were predominantly perceived as serious constraints followed by constraints of individual and both.

An animal can be maintained in a recommended manner by an individual. But, conservation of an indigenous breed is in the hands of community, government, research institutions and NGOs. Though the responsibility of breed conservation vests in the hands of community, the progressive change towards breed conservation should originates at individual farmer level.

Further, the results revealed the importance of community utilization of common resources like grazing land and ponds which could be achieved by Community Based Organizations (CBOs) and Farmers club. 
Based on the perception of farmers, the possible causes of prioritized constraints and strategies to overcome such constraints were discussed among the farmers and Subject Matter Specialist (SMS) group. Besides this, there are unfelt constraints also in Umblachery cattle farming. Hence the discussion was confined to farmers' perceived constraints only.

\section{Lack of grazing land}

The farmers stated that lack of grazing land is the most severe constraint in Umblachery breed cattle farming. Common grazing land available has degraded and become less productive due to encroachment and poor maintenance.

National Livestock Policy, 2013 of Government of India recommended that physical availability and production potential of pastures and grazing community lands have to be assessed for defining steps to rejuvenate, restore, improve and manage such lands by planting fodder trees and grasses. SMS group stated that it is the right time to encourage integrated land use planning with livestock as a component through gross-root level institutions like Panchayat Raj Institutions (PRI) will be beneficial. Further, there is a need to adopt the practice of land use with multiple crops in a sustainable manner.

\section{Improper maintenance of ponds}

In the villages of Umblachery cattle breed tract, ponds are also a common property for the whole rural community. Farmers worried about maintenance of ponds since maintaining exclusive ponds for livestock is still a subject of dispute among the farmers and non-farming community people. This paved way for lag in maintenance of the ponds. Dwindling water resources and declining rainfall every year are making the situation worse. To overcome this constraint, SMS group emphasized on implementing community water resource management practice through suitable extension service. Further, it recommended conducting periodical water quality test and estimating the egg and worm load of parasites in the ponds. They advocated the agencies involved in breed conservation to sensitize the farmers and trained to use the pond sustainably.

\section{Feed deficit}

Farmers knew that providing feed to the animals as such on the ground results in feed and fodder wastage. Research revealed that manger can save 30.00 per cent of fodder wastage compared to providing fodder as such on the ground. Farmers felt that the need of concentrate feeding is least important since they believed that Umblachery cattle can tolerate extreme feed deficit.

They were presently developing their awareness on importance of feed and fodder in cattle ration due to various schemes including "Fodder Minikit Scheme" of Animal Husbadry and various field level extension activities by Tamil Nadu Veterinary and Animal Science University.

The breeding tract of Umblachery breed cattle is the rice granary of Tamil Nadu. Complete utilization of agriculture residues and byproducts for feeding cattle can economize the use of available feed and fodder.

Hence, it is beneficial to promote agriculture by-products and waste as animal feed by enriching the proven technologies like treatment of straw with Urea and molasses along with silage. The ability of the Umblachery cattle to tolerate feed deficit should not be taken into lighter sense. Quddus (2010) found that crisis feed leads to reduction in native animals. 


\section{Mechanization}

In the group discussion, farmers revealed that the rapid mechanization in agriculture operation challenges the use and existence of draught animal. Farmers who are keeping Umblachery breed cattle know that animal power is generally affordable and accessible to small and marginal farmers and experience that use of native animals carries economic and sentimental value well beyond the farm gate. An average bullock is rated at 0.4-0.5 HP and a $35 \mathrm{HP}$ tractor is, therefore, supposed to replace at least 70 bullocks. Contrastingly, draught animals replace the agriculture machinery run on fossil-fuel (Dikshit and Birthal, 2010).

Farmers admitted that they preferred tractor in the place of Umblachery bullock for agriculture operations due to less involvement of cost and time in hiring the service of tractor. But, studies showed that individual tractor ownership is seldom profitable for small and marginal farmers but only for the large farmers. Hence, there is need for intensifying the social and basic scientific research relating to work animals.

\section{Dominance of fertilizer}

Farmers agreed that use of fertilizers is increasing to enhance the agriculture production in the recent decades. However, they agreed that they were aware of heavy use of commercial fertilizer pollutes the environment when they carried beyond the agro-ecosystem.

Weeds often reduce crop yields by 10.00 per cent or more which are more often controlled by mechanical tilling of the soil and the use of chemical methods (Pimentel et al., 1991). However, the energy inputs for the herbicides production are included; tillage turns out to be less energy-intensive (Clements et al., 1995).

\section{Inadequate farmers club}

Farmers emphasized the role of community based conservation in Umblachery cattle breed conservation. They stated that farmers' club and community based organizations meant for Umblachery cattle breed conservation can play a liaison role and evacuate the lag in conservation efforts. Presently, an association called, "Traditional Umblachery Cattle Farmers' Association" is actively functioning Umblachery village of Nagapattinam district and Korukkai village of Thiruvarur district in Tamil Nadu.

Though there are functioning farmers club and Self Help Groups in the Umblachery breed cattle prevalent villages, exclusive farmers' association intensifies the concerted efforts in promotion and improvement in breed conservation. Further, farmers possessing pure animals should come forward and recognize themselves to form breeder clubs, with direct link with the institutes involved in breed conservation. Government departments, NGOs, State agriculture and veterinary universities involved in breed conservation should encourage and support the farmer to such cubs and associations.

\section{Lack of bull}

Farmers expressed their dissatisfaction on lack of bull which has potential to cause adverse effect in breed conservation. They justified that they were unable to maintain pure bull owing to the cost involved in maintenance and suggested the Government to take the responsibility of maintaining and supply of pure bulls for breeding purpose in the breed conservation mission. In this regard, State Animal Husbandry and its exclusive Livestock farm to conserve Umblachery breed in Korukkai village of Thiruvarur district, Tamil Nadu Veterinary and Animal Sciences University and NGOs should accelerate its 
cooperative and coordinated efforts in breed conservation.

\section{Dominance of cross-bred population}

Farmers pointed out the indigenous cattle were preferred over crossbred due to their superior adaptability to local environmental stresses, rearing ease, low input and lesser proneness to disease (Quddus, 2010). Considering the production characteristics of cross-bred dairy animals, the tendency of maintaining crossbred animals by farmers is in increasing trend. Increase in cross-bred population competes with Umblachery breed cattle for common resource like grazing land, pond etc. It questions the existing relationship among the native breed farmers and cross-bred animal farmers. A native breed should not be considered as uneconomical based on its production parameters alone. The sustainability and potential of native animals have to be considered. Farmers are rearing their native animals with the sentimental and cultural value.

\section{Lower price of animals and its products on sale}

Though the farmers felt proud of the popularity and premium status given to the milk and milk products prepared from Umblachery cattle among the Cauvery delta people, they were unsatisfactory on the price given to their animals and its products. They expected to fetch a premium price for the products prepared from Umblachery breed cattle as like organic farm products. Considering the beneficial effect of consuming milk products prepared from native cattle milk, the consumers have to be sensitized to worth-pay a premium price for such products by suitable awareness and promotional activities. Like the tremendous response received by consumers on organic farm products, there is a promising scope for products prepared from Umblachery breed cattle which paves way to various entrepreneurial avenues for farmers.

\section{Unregulated marketing}

Farmers knew the importance of market in selling any products to the consumer. They showed their dissatisfaction experienced due to unregulated market and constraints faced while marketing their animals and its products. There is no regulated market facility for Umblachery cattle farmers except few shandies viz., Senbagarayanallur of Nagappattinam district and Thiruthuraippondi of Thiruvarur district. Farmers, largely, unaware of the value of their animals since they have limited access to information regarding markets. Regulation in marketing, shortening the marketing channel, removing the role of middleman and developing market intelligence among farmers will augment this condition.

\section{Lack of awareness about technologies}

Farmers believed that Umblachery breed in disease resistant and less input-intensive. The livestock farming activities are traditional in nature without challenging the agro-ecosystem and environment. Hence, they felt it was not required to adopt new technologies and restricted them to existing practices except few practices viz., deworming, vaccination and Artificial Insemination (AI). Lack of awareness about technologies developed in cattle farming was perceived as constraints and come under the least important third part of the prioritized constraints. Institutes and departments involved in breed conservation should carefully consider this belief to make them aware and adopt the farmer-friendly technologies developed to improve the profitability of native cattle farming like balanced ration, concentrate feeding, mineral supplementation, manger etc. 


\section{Strategies for Umblachery cattle breed conservation}

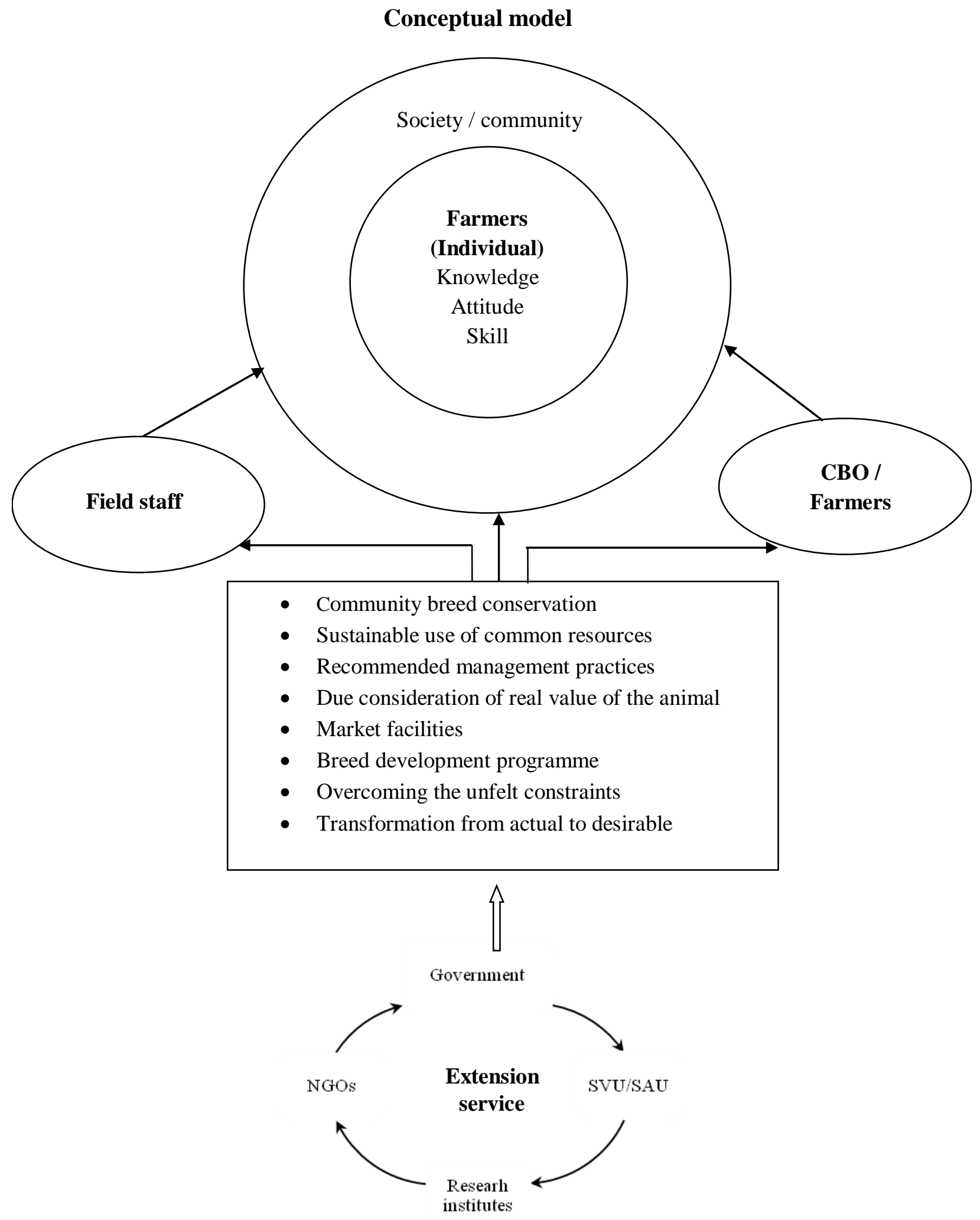


Table.1 Identification and grouping of constraints in Umblachery breed cattle farming

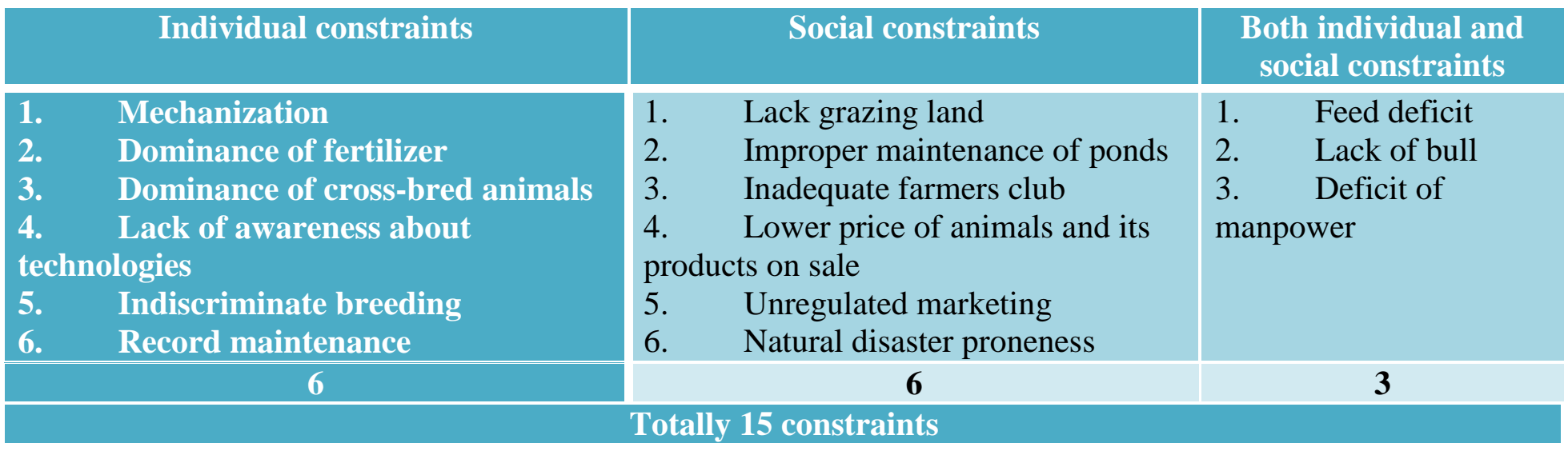

Table.2 Prioritizations of identified constraints in Umblachery breed cattle farming

\begin{tabular}{|c|c|c|c|}
\hline \multirow{3}{*}{$\frac{\text { Rank }}{\text { I }}$} & \multirow{2}{*}{\multicolumn{2}{|c|}{ Constraints }} & \multirow{3}{*}{$\begin{array}{c}(\mathrm{n}=30) \\
\text { Garret mean score } \\
79.37\end{array}$} \\
\hline & & & \\
\hline & Lack of grazing land & Social & \\
\hline II & Improper maintenance of ponds & Social & 72.30 \\
\hline III & Feed deficit & Both individual and social & 59.30 \\
\hline IV & Mechanization & Individual & 53.77 \\
\hline $\mathbf{V}$ & Dominance of fertilizer & Individual & 51.60 \\
\hline VI & Inadequate farmers club & Social & 49.17 \\
\hline VII & Lack of bull & Both individual and social & 48.75 \\
\hline VIII & Dominance of cross-bred animals & Individual & 43.56 \\
\hline $\mathbf{I X}$ & $\begin{array}{l}\text { Lower price of animals and its } \\
\text { products on sale }\end{array}$ & Social & 42.55 \\
\hline $\mathbf{x}$ & Unregulated marketing & Social & 39.44 \\
\hline $\mathbf{X I}$ & Lack of awareness about technologies & Individual & 38.86 \\
\hline XII & Indiscriminate breeding & Individual & 34.06 \\
\hline XIII & Record maintenance & Individual & 32.66 \\
\hline XIV & Natural disaster proneness & Social & 30.58 \\
\hline $\mathbf{X V}$ & Deficit of manpower & Both individual and social & 26.87 \\
\hline
\end{tabular}

\section{Indiscriminate breeding}

Tamil Nadu State breeding policy recommends Artificial Insemination (AI) in Umblachery breed cattle using Umblachery breed semen. However, preference of natural service by the farmers and lack of bull availability predisposes to indiscriminate breeding. Kidai, a traditional practice followed in Umblachery cattle rearing villages in which herd men collect and group the Umblachery cattle from the in and around village farmers and maintain in the harvested agricultural land during off-season for maintenance. In kidai, the practice of maintaining bull enables the animals in heat to become pregnant.

Herd men are unable to maintain pure breed bull because of the cost involved in its maintenance and its dwindling population. These predisposes to indiscriminate breeding. 
Promoting the traditional practice of maintaining kidai and providing quality bull to herder can avoid indiscriminate breeding. Practicing kidai requires proper herd management practices especially herd health management practices to minimize the healthoriented risk of keeping animals in group.

\section{Record maintenance}

Farmers felt that maintaining records is difficult for them since grazing and water requirement for keeping their animals involve common use of communal grazing land and ponds. Further, the benefits derived from Umblachery breed cattle farming are not always tangible. The practice of maintaining record should be inculcated among the farmers by sensitizing them about importance of record maintenance and training them to estimate the input cost involved while using common resources and benefit gained in the intangible form.

\section{Natural disaster proneness}

The native tract of Umblachery cattle is prone for natural disaster like flood, drought and tsunami. Considering the existence of farmers under continuous risk of such natural disaster every year and the activeness and sturdy nature of Umblachery breed, farmers felt it a less severe constraint. Further, they expressed their satisfaction on the war-footing service rendered by State Animal Husbandry and its peer departments and Tamil Nadu Veterinary and Animal Sciences University through its peripheral centres to livestock farmers by protecting and rescuing the livestock during disaster.

\section{Deficit of manpower}

Farmers conveyed their feeling of ambiguity about the paradoxical phenomenon existing between deficit of manpower and unemployment problem. Farmers felt that the syndrome of manpower deficit is spreading into the agriculture and animal husbandry activities in recent decades. It could be due to the improved educational status and the attitude towards better standard of living developed among the people. Hence, the gap between availability of manpower and unemployment problem in rural has to be studied and suitable measures should be implemented to break this paradox.

The above constraints identified by the Umblachery breed cattle farmers were in line with the findings of Quddus (2010).

\section{Methodological approach in conservation of Umblachery cattle breed}

The constraints in Umblachery breed cattle farming perceived by farmers have to be overcome in order to conserve the breed from genetic erosion. In this process, following methodological approach will be helpful.

Farmer-friendly information and technologies through extension service

Capacity building of the famer in practices like water resource management

Breed improvement after identification and evaluation

Improving access to suitably improved genetic material

Development and value addition of products to fetch premium price

Regulated market and sale

Strengthening farmer-consumer linkage

Improving access to local, regional, national and international market 
Effective veldt management and animal husbandry

Strenuous efforts in achieving coordinated and cooperative efforts among farmers

Inculcating the conservation attitude among the students

The declining indigenous cattle genetic resource day by day leads to genetic erosion. Withdrawal and decline in indigenous cattle is, no doubt, an incredible loss to rural livelihood and traditional agriculture. The value of native cattle should not be measured based on its production characteristics. Farmers rearing Umblachery breed cattle consider their animal as a source livelihood besides the existing sentimental and cultural attachment. Constraints prioritized in Umblachery cattle breed farming reiterates the importance of community people and their co-operation and co-ordination in breed conservation. Hence, steps have to be taken to encourage such community organization. Hence, it is the need of the hour to develop and implement prudent strategies to overcome the prioritized constraints identified through participatory approach for conservation of Umblachery cattle breed. In this mission, cooperative and coordinated efforts among the farmers and agencies involved have to be developed and intensified by strengthening the extension service.

\section{Acknowledgement}

The authors bestow their immense gratitude to Tamil Nadu Veterinary and Animal Sciences University (TANUVAS) for granting financial assistance and Directorate of Research, TANUVAS for motivation and concrete support. Equally, the authors extend their gratitude to "Umblachery Cattle Breeders Association", Umblachery, Department of Animal Husbandry,
Nagapattinam and Department of Veterinary and Animal Husbandry Extension Education (VAHEE), Madras Veterinary College (MVC), Chennai. Appreciation goes to Dr. N. Vimal Rajkumar, Assistant Professor, VAHEE, MVC, Chennai for his help at field.

\section{References}

Bishop, S.C., DeJong, H. and Gray, D. 2002. Opportunities for incorporating genetic elements into the management of farm animal diseases: Policy issues. Commission on Genetic Resources for Food and Agriculture, FAO, Rome. pp: 36.

Choubey, P. and Thomas, E. 2010. Native breeds of Madhya Pradesh: An overview, Proceedings of National Conference on Native Livestock Breeds and their sustainable uses, Vechur Conservation Trust, Kerala, 27 and 28 September 2010, pp: 34-39.

Dikshit, A.K. and Birthal, P.S. (2010). Environmental value of draught animals: Saving of fossil-fuel and prevention of greenhouse gas emission, Agri. Econ. Res. Rev., Volume: 23, July-December, 2010, pp: 227-232.

Quddus, M.A. and Amin, M.R. (2010). Constraints of native cattle genetic resource conservation and features of breeding system in representative areas of Bangladesh, Journal of Bangladesh Agriculture University, Vol.: 8(1), pp: 113-120.

Radhika, G., Raghavan, K.C. and Reghunandanan, K.V. (2010). Role of conservation of farm animal genetic resources in disease management of livestock, COVAS, Mannuthy, pp: 6469.

Ramaswamy, N.S. 1994 Draught animals and welfare Rev. sci. tech. Off. int. Epiz., 1994,13 (1), Pp. 195-216. 
Taneja, V.K. (2011). Report of the working group on animal husbandry \& dairying $12^{\text {th }}$ Five Year Plan (2012-17), Submitted to Planning Commission Government of India, New Delhi.

Thangaraju, P., Nainar, A.M. and R. Rajendran, 2001. Umblachery - A renowned draught cattle of tamilnadu. Proceedings of the Workshop on Indigenous Cattle and Their Role in the New Millennium, March 24-25, 2001, Erode, Tamilnadu, India, Pp. 13-19.

\section{How to cite this article:}

Kannadhasan, M.S., M. Kathirchelvan and Rajendran, R. 2018. Identification and Prioritization of Constraints in Umblachery Breed Cattle Farming Through Participatory Approach. Int.J.Curr.Microbiol.App.Sci. 7(11): 1100-1110. doi: https://doi.org/10.20546/ijcmas.2018.711.128 